\title{
The science and management of sex verification in sport
}

\author{
Ross Tucker (PhD) ${ }^{1}$ \\ Malcolm Collins (PhD) $)^{2,1}$ \\ ${ }^{1}$ UCT/MRC Research Unit for Exercise Science and Sports Medicine, Department of Human Biology, Faculty of Health Sciences, \\ University of Cape Town \\ ${ }^{2}$ South African Medical Research Council, Cape Town
}

\begin{abstract}
The verification of gender eligibility in sporting competition poses a biological and management challenge for sports science and medicine, as well as for sporting authorities. It has been established that in most sporting events, the strength and power advantage possessed by males as a result of the virilising action of hormones such as testosterone produce significant advantages in performance. For this reason, males and females compete largely in separate gender categories. Controversies arise as a result of intersex conditions, where the classification of individuals into male or female is complex. The present review provides the historical context to the debate, identifying the origins of gender verification as a means to deter cheating. It describes how various testing methods have been attempted, including physical examinations of genitalia, molecular techniques including genetic screening, and complex multidisciplinary approaches including endocrinological, genetic and gynaecological examination. To date, none appear to have provided a satisfactory resolution to the problem, and appear instead to have unfairly discriminated against individuals as a result of inappropriate application of testing results. Sporting authorities have formulated position stands for the management of such cases, but there is not absolute agreement between them and little evidence to support whether intersex individuals should or should not be allowed to compete in female categories.
\end{abstract}

\section{Introduction}

Gender verification of female athletes during international sporting events is not a recent issue. The possibility that men, who have in most cases an unfair biological advantage, could masquerade as female athletes has been a concern since women started competing

\section{CORRESPONDENCE:}

\section{Dr R Tucker}

UCT/MRC Research Unit for Exercise Science and Sports Medicine

PO Box 115

Newlands 7725

South Africa

Tel: +27216504570

Fax: +27216867530

E-mail: ross.tucker@mweb.co.za in individual athletic events. The history, methods and issues related to gender verification have been reviewed on a regular basis in the scientific literature over the years. ${ }^{1-6}$ Although athletes from many nations have been subject to the various verification methods used over the years, this issue has, from a South African perspective, recently been extensively debated in the public domain in an unprecedented way. Caster Semenya, the women's $800 \mathrm{~m}$ gold medallist at the Berlin world championships during August 2009, refuelled the debate on gender testing in sport. The purpose of this review is to investigate the historical and current practises and understanding of gender verification within the medical and scientific community.

\section{Gender, sex and performance}

The term gender verification has predominately been used in the scientific literature ${ }^{1-5}$ and by various sporting bodies, including the International Olympic Committee (IOC) $)^{5}$ and International Association of Athletics Federations (IAAF) ${ }^{7}$ to describe and debate the issue of testing and verifying that only eligible athletes compete in female events. Gender is however a social construct comprising not only biological but also social and other non-biological differences between males and females. ${ }^{8}$ The term sex, on the other hand, refers solely to the biological difference between individuals and in the vast majority of cases can be divided into two clear categories: male and female. ${ }^{8}$ Although we recognise that gender issues are important in the sporting arena, the term sex verification or testing will be used in this review to highlight the biological differences between male and

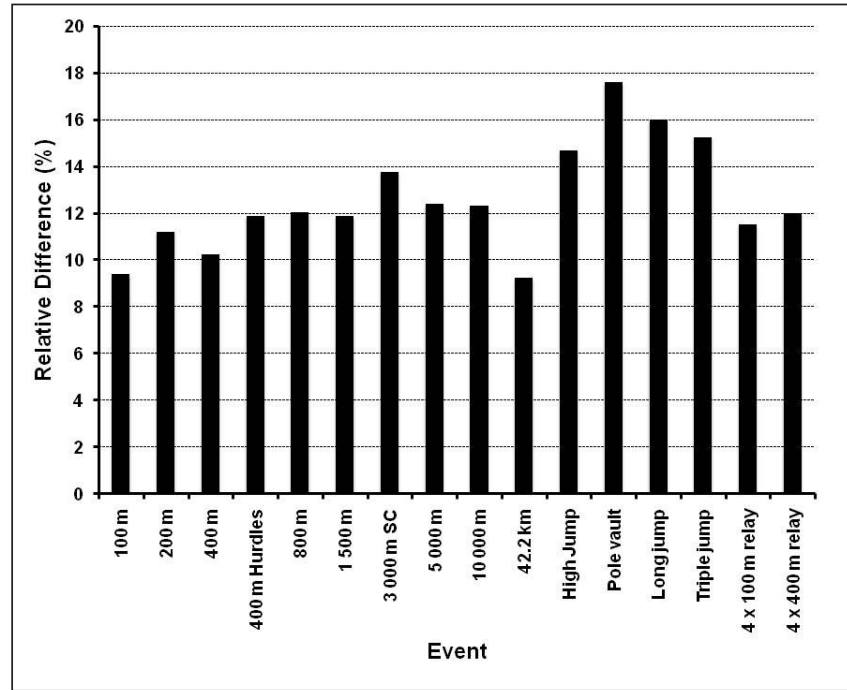

Fig. 1. Relative differences between male and female world records for various athletic field, track and road events. The world records for the individual male events is on average $12.6 \pm 2.3 \%$ (ranging from $9.2 \%$ to $17.6 \%$ ) faster than the female events. SC = steeple chase; $\boldsymbol{m}=$ metres; $\mathbf{k m}=$ kilometres. 
female athletes which generally give male athletes an unfair advantage over their female counterparts. ${ }^{9}$

With the exception of the equestrian events, where male and female athletes compete together in all Olympic events (www. olympic.org), male athletes have a performance advantage over female athletes. This is illustrated by a comparison between male and female world records in track and field events, as well as the standard marathon, where men's world records are between $9 \%$ and $18 \%$ better than women's records for those events allowing a direct comparison to be made (Fig. 1). Similar performance advantages can be measured in cycling, speed-skating and swimming events (data not shown). As a result of this performance difference, women compete in a category separate to men to ensure equality of competition. In addition to sex, weight classes are also used to categorise athletes in open competition where weight differences are believed to have a biological advantage. These sports include, among others, boxing, weight lifting, and the martial arts disciplines (www.olympic.org). Unlike weight, which can be accurately determined using a calibrated scale, the science of sex verification is more complex and controversial.

\section{Stop men competing as women}

Athletes, coaches, officials, the media and spectators have always been aware and concerned that there is the potential that male athletes would deliberately disguise themselves as women and compete as female athletes in individual events. This issue attracted much media attention during the 1936 Berlin Olympic Games where Herman Ratjien competed in the high jump for Germany as Dora Ratjen. ${ }^{3}$ Although 'Dora' finished only 4th in that competition, 'she' eventually set a world record at the European Championships 2 years later (http://en.wikipedia.org/wiki/Dora_Ratjen). It has been alleged that Ratjen was forced to disguise himself as a female athlete by the Nazis. ${ }^{3}$ It is also reported that due to abnormalities with his genitalia, Herman was registered as Dora at birth and raised as a girl (http://en.wikipedia.org/wiki/Dora_Ratjen). This case, as well as other accusations of male athletes masquerading as females during the Berlin games, ${ }^{6}$ as well as rumours and innuendos during the 1960 Rome Olympic games prompted the IOC and IAAF to establish rules to stop men cheating during competition thereby enabling female athletes to compete on an equal basis. ${ }^{1-4,6}$

\section{Sex verification - not a simple problem}

The Berlin games also highlighted that sex verification is not a simple scientific and medical problem to solve. Polish-born Stella Welsh (Stalislawa Walasiewicz), who had moved to the USA in 1932, and the American Helen Stephens both competed in the women's $100 \mathrm{~m}$ sprint. ${ }^{6}$ Walsh had won the $100 \mathrm{~m}$ gold medal in 1932 , and was speculated by many to be male, receiving the nickname 'Stella the Fella' from the media (http://en.wikipedia.org/wiki). ${ }^{6}$ Helen Stephens beat Walsh in the $100 \mathrm{~m}$ event at the 1936 games, and although there was no official gender testing during the Games, Stephens passed a crude examination of her external genitalia after she was accused of being a male by Stella Welsh. ${ }^{6}$ Interestingly, Stella Welsh was discovered to have ambiguous genitalia and abnormal sex chromosomes during an autopsy after she was a victim of a shooting incident in $1980,{ }^{6}$ highlighting that sex verification during sporting events would not only identify those cheating but also athletes with a rare intersex condition. An unanswered question is whether these intersex conditions might confer a sporting advantage to certain individuals who compete as females, and whether this advantage should form the basis for exclusion from female competition. As will be discussed in this review, one cannot exclude the inevitable possibility that female athletes with a rare intersex disorder could be unfairly disqualified and barred from competing in athletic events, especially if inappropriate testing is done and the issue is poorly managed. In addition, the potential for long-term psychological harm to the athlete concerned can not be under-estimated.

\section{Disorder(s) of sex development}

Intersex is a rare disorder which is usually identified at birth by the atypical appearance of the genitalia, making sex assignment difficult. The incidence has been estimated as approximately 1 in 5000 births, but can be as high as $1.7 \%$ when conditions such as Turner's and Kleinfelters's syndrome are included. ${ }^{6}$ The classification of the intersex disorders is challenging and controversial, but these conditions were recently grouped under the collective name disorder(s) of sex development (DSD) by the international intersex consensus conference. ${ }^{10}$ DSD is not a single disorder but rather a spectrum of conditions ranging from those with ambiguous external genitalia, those with external female genitalia and varying degrees of internal testis. $^{2,10}$

\section{History of sex verification}

The current practices and beliefs with respect to the science and management of sex testing in sport need to be understood in its historical context. When sex verification was first introduced in international sporting competition during the early 1960s, female athletes underwent physical examinations where they stood before a committee of experts, in what became known as the 'nude parade'. 6 This resulted in widespread resentment by the athletes, prompting the IOC to seek other simpler, objective and more dignified methods of sex testing. The sex chromatin (or buccal smear) test, which requires the identification of Barr bodies during microscopic examination of cells scraped from the inner lining of the athlete's cheek, was developed and first introduced during the 1968 Mexico City Olympic Games.

Human DNA is packed into 22 pairs of autosomes and one pair of sex chromosomes in most cell types in our bodies. Under normal circumstances, females possess two $X$ sex chromosomes and males one $\mathrm{Y}$ chromosome and one $\mathrm{X}$ chromosome. The extra female $\mathrm{X}$ chromosome is inactivated during development to form a Barr body in the nucleus of cells. The presence of a Barr body is therefore an indication that the cells being tested originate from a female, whereas the absence of a Barr body indicates that the cells originated from a male. Since there is a direct relationship between chromosomal and anatomical sex for the majority of people, this test would be accurate in most cases. There are however a number of genetic disorders which interfere with the normal process of sex development and lead to contradictory findings between anatomical and chromosomal sex. ${ }^{10}$ As mentioned previously, these conditions are collectively referred to as disorders of sex development (DSDs). ${ }^{10}$ It is the potential identification of such an individual athlete during sex testing during athletic events that is problematic.

DSDs can be caused by several combinations of abnormal sex chromosomes. ${ }^{6,10}$ For example, individuals with only one $X$ sex chromosome have a female appearance (Turner's syndrome), while individuals with two $X$ and one $Y$ chromosome ( $X X Y$, Klinefelter's syndrome) are usually infertile men. ${ }^{2}$ The Barr body test would identify these individuals as female, which would allow men with Klinefelter's syndrome to compete as females. Women with Turner's syndrome would 'test as men' due to the absence of a second sex chromosome and therefore a Barr body. It should however be noted that not all athletes with abnormal sex chromosomes 
would potentially have a biological advantage over their female counterparts with normal sex chromosomes, and both Turner's and Klinefelter's syndrome would be unlikely to confer a performance advantage. Rather, it is disorders affecting androgen function, which are discussed subsequently, that present the problem of potential performance advantages to females. It is also possible for different cells in a individual to contain different sex chromosomes. ${ }^{3}$ This is referred to as mosaicism, where some cells may present with $X X$ and $X X Y$ chromosomes. Other possibilities include $X X$ and $X Y$ cell combinations, or $X$ and $X Y$ cell combinations. ${ }^{3}$

An illustration of this complexity and the implications for testing is the case of Ewa Klobukowska, a Polish sprinter who won gold and silver in the women's $100 \mathrm{~m}$ and $200 \mathrm{~m}$ sprints at the 1966 European Athletics Championships in Budapest. ${ }^{11}$ She was also a member of the winning team in the $4 \times 100 \mathrm{~m}$ relay event. Prior to the Budapest championships, she won gold and bronze medals at the 1964 Tokyo Olympic Games for the 4X100 m relay and $100 \mathrm{~m}$, respectively (http:// en.wikipedia.org/wiki/Ewa_Klobukowska). Although she passed a gynaecological exam during the Budapest championships, she was the first Olympic medal-winning athlete to fail a sex chromatin gender test in 1967. Although her disorder was correctly, due to confidentiality and medical ethics, never officially revealed, she was nevertheless stripped of her medals. ${ }^{11}$ It has been alleged that this was a result of an $X X / X X Y$ mosaicism, although this was never officially revealed (http://en.wikipedia.org/wiki/Ewa_Klobukowska). ${ }^{11}$ The implication is that Barr body analysis is more likely to exclude athletes unfairly than to detect those who cheat.

In addition to these conditions, there are also individuals with a female appearance who have a DSD with male sex chromosomes the so-called $X Y$ females. ${ }^{1,6}$ These individuals have apparently normal male chromosomes, but develop to adulthood as women. The disorders responsible for this phenotype can broadly be divided into (i) disorders in androgen synthesis or action and (ii) disorders of testicular development. ${ }^{6}$ An example of the former group of disorders is complete or partial androgen insensitivity syndrome (AIS). ${ }^{1}$ Individuals with AIS have testes (which can be internal) that produce normal amounts of testosterone. However, abnormal androgen receptors, which are partly or completely insensitive to androgens, result in the development of secondary female characteristics and musculature. Various grades of AIS exist, ranging from complete AIS to partial AIS with a very mild impact on sexual development. ${ }^{1}$ This may impact on performance, since androgens are largely responsible for virilisation, including muscle development, which may confer a performance advantage. Individuals with partial AIS may thus develop sexual characteristics of a female, and be identified and raised female, while possessing some level of athletic performance advantage.

A further complication is somatic mosaicism of the androgen receptors, as a result of de novo mutations after the zygotic stage. ${ }^{12}$ These mutations may result in different levels of sensitivity to androgens, leading to virilisation at puberty, despite childhood development as female with respect to the genitalia. ${ }^{12}$ This may have further implications for performance. Santhi Soudarajan, an Indian middle distance runner, was stripped of her 2006 Asian Games silver medal in the $800 \mathrm{~m}$ event after failing gender testing, allegedly as a result of this condition (http://en.wikipedia.org/wiki/ Santhi_Soudarajan).

\section{Genetic screening increases in complexity}

Although the IAAF stopped compulsory sex testing in $1991,{ }^{3}$ the IOC continued to screen all female participants, but replaced the Barr body test with a more complex screening process which involved
PCR analysis to detect the SRY gene, which is found on the male $Y$ chromosome. ${ }^{3}$ The product of this gene was thought to be essential for the differentiation of the internal foetal gonad into testis, which ultimately produces the male phenotype. ${ }^{6}$ It is now known that this test also has limitations, since other genes are also required for testis development and in addition, it has been reported that individuals with $\mathrm{XX}$ sex chromosomes, and therefore no SRY gene, can have testes. $^{6}$ Further, it is also possible for the SRY gene to exist on the $\mathrm{X}$-chromosome as a result of translocations during meiosis. ${ }^{11}$

This test was used during the 1992 Winter Olympics and 1996 Atlanta Olympic Games, where all women competitors submitted a sample which was analysed. In 1992, 2406 tests were conducted, with 5 positive samples for the SRY gene and in 1996 there were 8 positive SRY gene test out of 3387 tests. $^{3,5}$ These individuals were entered as females, but possessed the SRY gene and in theory, excluding a translocation event during meiosis, a Y-chromosome. The incidence (approximately 1 in 400) during the 1992 and 1996 games using the SRY gene test were similar to the incidence reported from 1972 to 1990 , where 13 positive tests were reported out of 6561 (approximately 1 in 500). ${ }^{1,2}$

Seven of the 8 athletes in the Atlanta games had AIS and the eighth athlete had a condition called $\alpha$-5-reductase deficiency, ${ }^{3,5,6}$ which results in the failure to convert testosterone to dihydrotestosterone, an androgen which is essential for the in utero development of external male genitalia. These individuals develop externally as females, despite having high levels of testosterone and internal testes. As is the case with AIS, the elevated levels of testosterone, relative to other females, is thought to confer some performance advantage, though no studies have quantified the possible magnitude of this difference. In the 2000 Olympics, all 8 athletes were cleared to compete, though the reasons for this clearance were never disclosed. 5,6 There are theoretical reasons why athletes with both partial AIS and $\alpha-5$ reductase deficiency may have performance advantages, but we are not aware of the grounds for clearing these athletes for competition. Eventually the IOC stopped compulsory testing of female athletes in 1999. ${ }^{3,5}$

Interestingly, it has recently been reported that since 2005, four athletes had been asked to retire from athletics by the IAAF as a result of gender testing, while three others had been permitted to continue their careers (/www.sport24.co.za/Content/OtherSport/ 262/97ea563d0618444c808b8057e9c020a6/10-09-2009-02-32/ Semenya_made_to_wait). There have, for reasons of medical confidentiality, been no further descriptions or explanations of these cases, and the grounds for the different outcomes of the testing process for these individuals. This highlights the complexity of the actions that are taken against athletes, since no data exist on how DSDs may confer a performance advantage to athletes.

In an excellent essay entitled 'Intersex and the Olympic Games', Richie et al. ${ }^{6}$ summarise the effects of gender testing as follows: 'As our understanding of gender and sexual identify increased ..., it became increasingly apparent to scientists and athletes alike that determination of sex is derived from far more than our genotype. ... Gender testing was initially welcomed by female athletes as a method of preventing "cheaters". However, it has become apparent that the discrimination against those with DSD was unfair and detrimental to the sport.' They continue to mention that: 'Gender testing in athletics has never identified an individual deliberately misrepresenting their gender. Testing has, however, created controversy and embarrassment for a significant number of female athletes competing, often unknowingly, with some form of intersex disorder. Indeed, there is no evidence that female athletes with DSDs have displayed any sports relevant physical attributes which have not been seen in biologically normal female athletes. 
However, numerous female athletes have been unfairly barred from competing'. 6

\section{IAAF consensus statement}

As a result of controversies surrounding testing and the potential for unfairly barring athletes from competing, the IAAF Medical and AntiDoping Commission published the IAAF Policy on Gender Verification in $2006 .{ }^{7}$ In it they state that there will be no compulsory, standard or regular gender verification during IAAF-sanctioned events. However, the policy continues to state that in resolving cases that may arise due to any 'suspicion' or if there is a 'challenge', determination should not be done solely on laboratory-based sex determination. Instead the athlete concerned could be asked to attend a medical evaluation by a multidisciplinary panel of experts consisting of a (i) gynaecologist, (ii) endocrinologist, (iii) psychologist, (iv) international medicine specialist, and $(v)$ expert on gender/transgender issues.

To our knowledge there are no published studies in the scientific literature that have specifically shown or suggested that any of the DSDs give an unfair advantage to the individual. Instead the IAAF groups the DSD conditions into two broad categories, (i) those that accord no advantage over other females and (ii) those that may accord some advantage but are nevertheless acceptable. ${ }^{7}$ The former category consists of complete or near-complete AIS, gonadal dysgenesis and Turner's syndrome. The latter group consists of congenital adrenal hyperplasia, androgen-producing tumours and anovulatory androgen excess (polycystic ovary syndrome). ${ }^{7}$ In all cases, the IAAF states that if testes are present, they should be removed to avoid malignancy. ${ }^{7}$

\section{The Canadian Academy of Sports Medicine (CASM) recommendations}

The 1997 CASM position statement on sex testing (gender verification) in sport suggests that there is no evidence that the initial justification and reasons for sex testing, which were to prevent men from masquerading as female athletes, are relevant today. ${ }^{9}$ They mention that $(i)$ the use of communal dressing rooms and showers, (ii) the clothing worn by female athletes, (iii) current protocols used for drug testing in urine, and (iv) the athlete's personal and sporting history, significantly reduces the likelihood of men competing as women at an international level.

The CASM also recommends that: 'Individuals raised as females and are psychologically and socially females from childhood should be eligible to compete in women's competition regardless of their chromosomal, gonadal and hormonal sex' ${ }^{9}$ Furthermore, they recommend that: 'Women athletes who have developed greater than average muscle mass, whether due to extreme training programmes or to genetic abnormalities such as congenital adrenal hyperplasia, incomplete/partial AIS or chromosomal mosaicism should be accepted as part of the normal range of variation, similar to individuals who have grown to extreme heights. ${ }^{9}$ The CASM agrees with the current practice of disqualifying women (and men) who have increased their muscle mass by using steroids or other banned performance-enhancing drugs. ${ }^{9}$

This position is likely to be contentious among some female athletes, since it holds that these individuals should be accepted as falling within the 'normal range of variation'. This definition of 'normal variation' challenges the boundary that exists between male and female competitions which, as we have described, is not as clearcut or easily identifiable as was first thought when sex testing was introduced.
Theoretically, DSDs which result in elevated testosterone levels may confer some performance advantage over other females, if the testosterone has a biological effect on the tissues. However, evidence has not yet been provided, primarily due to the rarity of such conditions, as well as ethical matters pertaining to confidentiality. It may prove impossible to determine conclusively whether performance advantages exist or not. Whether any performance advantage that may exist falls within normal variation is also a contentious issue, because, referring to the CASM position stand example, athletes do not compete in categories of height. The classification of athletes into male and female categories requires that some boundary between the classes remain in place, and the contention is around whether normal variation may in fact move an individual across this boundary, and should be disallowed. At present, there is no scientific evidence to support or refute this position.

\section{Conclusion}

The process and management of sex verification is enormously complex and poses challenges not only to the biological description of male and female, but also to social and cultural characterisations of gender and sex. The process of verification has evolved over 70 years, having first begun as a means to deter deliberate cheating, and then evolving into a process that aims to ensure fair competition in the face of conditions that are thought to confer performance advantages. However, while a range of conditions and disorders have been identified, authorities are seemingly no closer to establishing precisely how these conditions affect performance, and many athletes appear to have been unfairly excluded from competition. Recognising this, a sub-committee was formed at the 13th Biennial Conference of the South African Sports Medicine Association (SASMA) in Durban on 21 - 23 October 2009 to draft a position statement on gender and sex verification for the South African context.

\section{REFERENCES}

1. Ferguson-Smith MA, Ferris EA. Gender verification in sport: the need for change? Br J Sports Med 1991;25(1):17-20

2. Simpson JL, Ljungqvist A, de la CA, Ferguson-Smith MA, et al. Gender verification in competitive sports. Sports Med 1993;16(5):305-315.

3. Dickinson BD, Genel M, Robinowitz CB, Turner PL, Woods GL. Gender verification of female Olympic athletes. Med Sci Sports Exerc 2002;34(10):1539-1542.

4. Reeser JC. Gender identity and sport: is the playing field level? $\mathrm{Br} \mathrm{J}$ Sports Med 2005;39(10):695-699.

5. Genel M, Ljungqvist A. Essay: Gender verification of female athletes. Lancet 2005;366 Suppl 1:S41.

6. Ritchie R, Reynard J, Lewis T. Intersex and the Olympic Games. J R Soc Med 2008;101(8):395-399.

7. IAAF policy on gender verification. IAAF Medical and Anti-Doping Commission; 2006.

8. What do we mean by "Sex" and "Gender"? World Health Organization; 2009.

9. Doig P, Lloyd-Smith R, Prior JC, Sinclair D. Position Statement: Sex Testing (Gender Verification) in Sport. Canadian Academy of Sports Medicine; 1997.

10. Lee PA, Houk CP, Ahmed SF, Hughes IA. Consensus statement on management of intersex disorders. International Consensus Conference on Intersex. Pediatrics 2006;118(2):e488-e500.

11. Strachan T, Read AP. Human Molecular Genetics 3. 3rd ed. Garland Publishers; 2004.

12. Kohler $\mathrm{B}$, Lumbroso $\mathrm{S}$, Leger $\mathrm{J}$, et al. Androgen insensitivity syndrome: somatic mosaicism of the androgen receptor in seven families and consequences for sex assignment and genetic counseling. J Clin Endocrinol Metab 2005;90(1):106-111. 